NOT FOR QUOTATION

WITHOUT PERMISSION

OF THE AUTHOR

\title{
THE LUSTING AND CLASSIFYING OF HAZARDOUS WASTES
}

Michael Dowling

Joanne Linnerooth

April 1984

WP- $84-26$

Working Pupers are interim reports on work of the International Institute for Applied Systems Analysis and have received only limited review. Views or opinions expressed herein do not necessarily represent those of the Institute or of its National Member Organizations.

INTERNATIONAL INSTITUTE FOR APPLIED SYSTEMS ANALYSIS 2361 Laxenburg, Austria 


\section{PREFACE}

This paper has been produced as part of ILASA's hazardous waste management work, which is the main component of the Institutional Settings and Environmental Policies project. The overall aim of this work, reflected in this paper, is to systemize our understanding of interactions between institutional and technical factors in policy making and implementation. The influence of institutional processes upon technical knowledge built into policy has been increasingly recognized. However, it has yet to be adequately systematized in comparative research on different regulatory systems. Institutional structures cannot be easily transplanted from one culture to another. Nevertheless, through the normal fux of policy, institutional development slowly occurs anyway, in more or less ad hoc fashion. Comparative insight may help to direct reflection and adaptation in more deliberate and constructive ways.

This paper forms one chapter of an intended book on hazardous waste management. The reader will therefore notice references to other draft chapters in this study which are also being published separately, and which are available from IIASA.

I would like to thank those policy makers and others who generously gave of their time and experience in the many interviews which form a substantial input to this work. A full list of acknowledgements will eventually be published.

Brian Wynne

Research Leader Institutional Settings and Environmental Policies 


\section{THE IJSTING AND CLASSIFYING OF HAZARDOUS WASTES}

\section{Michael Dowling and Joanne Linnerooth}

\section{INTRODUCTION}

Central to any regulatory program designed to manage the disposal of hazardous wastes is the development of a system for defining and distinguishing hazardous wastes from the plethora of non-hazardous wastes. Such a system involves both defining the concept of waste in general and distinguishing that subset of wastes considered "hazardous" and thus requiring special control. This process would seem to be straightforward, involving the appropriate scientific expertise to identify which wastes are potentially harmful to health or the environment, and listing and classifying them in some logical way. Economic efficiency arguments would suggest that this process would include developing a "degree of hazard" system, i.e., identifying those wastes which are most hazardous, less hazardous, etc., so that resources could be efficiently allocated to control the most hazardous wastes more stringently, and so on.

In reality, this process has not been straightforward at all. In the variety of industrialized countries that have attempted to deal with the problem, attempts to define and classify hazardous wastes have been characterized by: lack of information; scientific uncertainty; differences in legal versus administrative or scientific definitions; trade-offs between comprehensiveness, precision, and implementability; consideration of environmental protection and cost to industry; problems in standardization and the need for flexibility; and finally wide differences in the political cultures that affect responses to all of these difficulties. As a result, definition and classification schemes vary 
significantly between countries and even between states or regions within countries, and are designed to meet different administrative purposes and institutional constraints. Although there has been strong pressure towards international harmonization, coordinating bodies have tried but failed to develop an internationally accepted system. In the report of a recent North Atlantic Treaty Organization (NATO) study of hazardous waste management, Dr. Bernd Wolbeck, one of the Federal Republic of Germany's leading hazardous waste experts has remarked:

"During the past ten years, the political and regulatory discussion has intensively focused on the questions of what constitutes a hazardous waste. Despite these efforts, an international consensus could not be achieved on the issue. One of the primary reasons for this seems to me that the question has often been posed without indicating clearly enough the legal requirements which the definition and classification were to satisfy."[1]

British hazardous waste expert Ted Finnecy has observed that, in addition to legal requirements, hazardous waste classification schemes depend upon a complex structure of regulatory and administrative purposes that may vary significantly between countries.[2] Understanding how these variations arose and how explicit or implicit criteria for listing and classifying wastes were chosen reveals much about the interaction between institutional constraints and science in developing environmental control regulations in general.

To examine some of these issues we will first outline the various types of classification systems that can be employed. We will then turn to case studies of how hazardous waste classification systems were developed in two key countries, the United States and the Federal Republic of Germany (FRG). The U.S. and the FRG were two of the first countries to develop hazardous waste control systems. Within Europe, the FRG has served as a model for other countries, and in the U.S., the system developed by the Environmental Protection Agency (EPA) has been imposed as a model for the control systems in the various 
states. In addition, we will briefly compare them with the classification scheme of Austria that has been influenced by the FRG. Finally, we will discuss some of the key issues illustrated by these cases and their significance in terms of the general implementation problems of such control legislation.

\section{TYPES OF HAZARDOUS WASTE CLASSIFICATION SYSTEMS}

Before examining the classifications systems adopted by specific countries it is useful to outline the various kinds of classification systems that can be used to regulate hazardous waste. One can define hazardous waste by: general characteristics, the presence of hazardous constituents, and determining that specific wastes are hazardous and listing them.[3]

\section{Hazardous Faste Characteristics}

In this approach, general hazardous waste characteristics, such as flammability, corrosivity, toxicity, etc., are defined. Specific test procedures are given to determine if a waste meets the criteria. For example, with regard to flammability a threshold flash point temperature is given, above which a waste is considered hazardous.

\section{Hazardous Constituents}

In this approach the presence of specific toxic chemical constituents, possibly above a certain concentration, define a waste as hazardous. Wastes must be tested for the presence of such constituents.

\section{Hazardous Faste lists}

The most common approach to waste classification is the listing of specific wastes identified as hazardous, the so-called inclusive list. No testing is required. If the waste is on the list it is automatically regulated. Several types 
of inclusive lists can be used.

- Lists of "generic" hazardous wastes, that is wastes arising in many different industries or from many sources. Examples are "waste lubricating oils" and "halogenated organic solvents";

- Lists of industry specific wastes, such as pickling liquor from steel manufacturing":

- Lists of specific chemical products, which if discarded, are to be considered hazardous, such as DDT or chlordane.

Another approach, previously used by the United Kingdom in its initial hazardous waste regulations is the exclusive list. An exclusive list describes wastes that are not hazardous and therefore not regulated. (For a further discussion of exclusive lists see in this volume Ley. p.--) In the cases that follow, we will examine how these classification schemes were developed and used in the various countries.

\section{THE UNITED STATES}

The Resource Conservation and Recovery Act (RCRA) of 1976 is the formal legislation for controlling hazardous wastes in the United States. This legislation replaced the previous Solid Waste Disposal Act of 1965 and placed more emphasis on "resource recovery" or the recycling of waste components such as glass, metal, aluminum, etc. Subtitle $C$ of the Act focused on the control of hazardous waste, which at the time of its passage was viewed as the least significant section of the law. Coming nearly two years before the widely publicized Love Canal episode, government, industry, and environmental groups generally did not view the problem of hazardous wastes as a separate and distinct issue from the more general problem of handling and recycling solid industrial and municipal waste. Therefore, the Act was passed virtually unopposed by industry and unnoticed by environmental groups. Its passage, to a large extent, resulted from the efforts of a few individual Congressmen who felt that a law concerning solid wastes was the one unfinished piece of environmental 
protection legislation, after the passage in the U.S. of the Clean Air and Clean Water Acts in the early 1970's. Ironically, the EPA had little involvement in the preparation and passage of the legislation, yet it was later charged with the task of developing the regulatory system outlined in it.[4]

Subtitle C of RCRA lays out a broad framework for the comprehensive control of hazardous wastes with five major elements:

1. a federal classification system;

2. a trip ticket control system;

3. federal standards for generators, transporters, and disposal facilities;

4. a permitting program;

5. the authorization of state programs as substitutes for the federal program.[5]

i

The details of the framework were developed within the EPA and promulgated as regulations on May 19, 1980.

\section{The U.S. Definition of Hazardous Waste}

Material cannot be classified as 'hazardous waste' unless it first qualifies as a 'waste', or more specifically as a 'solid waste', defined in Section 1004 (27) of RCRA as

"any garbage, refuse sludge... and other material including solid, liquid, semisolid, or contained gaseous material resulting from industrial, commercial, mining and agricultural operations, and from community activities."

Interestingly, the U.S. definition of 'solid' waste includes liguid and gaseous wastes. In other words, by "solid" the Act means "packageable wastes" as opposed to those discharged into the air and water which are regulated under the Clean Air and Water Acts. (For a discussion of the problems in defining the concept of "waste", see in this volume Wynne and Thompson, page -). Hazardous waste is defined in Section 1004(5) of RCRA as:

"a solid waste, or combinations of solid wastes, which because of its quantity, concentration. or physical, chemical, or infectious 
attributes may:

A. cause, or significantly contribute to an increase in mortality or an increase in serious irreversible or incapacitating illness, or

B. pose a substantial present or potential hazard to human health or the environment when improperly treated, stored, transported or disposed of, or otherwise managed."[6]

Section 3001 of RCRA directed the EPA to develop criteria for identifying the characteristics of hazardous waste and criteria for listing particular hazardous wastes. In adopting these criteria, Section 3001 required the EPA to take account of "toxicity, persistance and degradability in nature, potential for accumulation in tissue, and other related factors such as flammability, corrosiveness, and other hazardous characteristics." In its regulations to implement this legislation, the EPA developed a two-tiered system for a generator of waste to determine if a waste is hazardous. The generator can first check if the waste appears on one of the EPA's published lists or if the waste is not listed, test the waste for four designated characteristics of hazardousness. We will discuss each of these tiers in turn.

\section{The EPA Lists}

The EPA selected two sets of criteria for listing hazardous waste: criteria for wastes that are acutely hazardous wastes and criteria for other toxic wastes. The criteria for listing acutely hazardous wastes were intended by the EPA to meet Part A of the statutory definition, i.e., identify wastes which may "cause or significantly contribute to an increase in serious irreversible or incapacitating illness." The EPA defined these waste to be either: (a) fatal to humans in low doses, or (b) have animal toxicities of oral LD 50 (lethal dose for $50 \%$ of the animals tested) of less than $50 \mathrm{mg} / \mathrm{kg}$ in rats, inhalation LD 50 of less than 2000 $\mathrm{mg} /$ cubic meter in rats, or dermal $\mathrm{LD} 50$ of less than $200 \mathrm{mg} / \mathrm{kg}$ in rabbits. These animal toxicities were equivalent to U.S. Department of Transportation, Consumer Product Safety Commission, and National Academy of Sciences 
definitions for poisonous or acutely toxic substances.[?]

Other wastes, that were not acutely toxic, were to be listed if they were carcinogenic, mutagenic, teratogenic, phytotoxic or toxic to aquatic species. Using these characteristics, the EPA identified over 380 chemical substances that, if present in a waste, would make it hazardous, unless it could be shown that the waste was not hazardous after consideration of 11 factors. The factors included, for instance, the nature of the toxicity of the constituent, the concentration of the constituent in the waste, the quantity of waste generated, and "such other factors as may be appropriate."[8] As a result, the Administrator of the EPA had a large measure of discretion in deciding whether a waste must be listed or not. Although any of these 11 factors could be used to justify not listing a waste, the actual process was described by the EPA as follows. If a waste contained one of the 380 constituents identified as hazardous, it was then analyzed to see if the constituent or constituents were present in significant concentrations. If so, the waste was most likely listed, unless there was "a very strong likelihood that the constituents were incapable of migrating even if improperly managed."[9] The actual compilation of the hazardous waste list began with the identification of toxic constituents. However, toxicity testing, especially for carcinogens, is a complicated, costly procedure. Tests must be carried out under carefully controlled laboratory conditions and at best produce results that usually require a judgement as to their significance. Fortunately for the EPA, other environmental legislation had required that many toxic constituents be identified. The EPA relied almost exclusively on these lists developed for other environmental regulations to compile its list of 380 toxic constituents for RCRA Specifically, it took approximately 300 entries from the list prepared for the Clean Water Program, six or so from the Clean Air Program, approximately 20 from the EPA List of Toxic Substances, and approxi- 
mately 20 from those identified by the EPA Cancer Assessment Group.[10]

Since data from the Clean Water Program were used so extensively, it is interesting to note how this list was compiled. The history of this list can be traced back to 1974 when environmental groups sued the EPA for not implementing Section 307 of the Clean Water Act, which required the EPA to identify and regulate specific toxic water contaminents. In reaching a compromise with environmental groups the EPA hastily compiled an initial list from reviews of the scientific literature. One source provided the bulk of the information, a book titled Water Quality Criteria, edited by McKee and Wolf. It was first published in 1952 and has been repeatedly revised up to its last edition in 1971. The book contains a survey of potential toxic contaminents of water with reference to the U.S. and foreign literature, giving general information on effects to aquatic life (not humans or other mammals)

With the help of these identified toxic constituents, the EPA developed its list of hazardous wastes. In this list, the EPA described wastes in two ways. First, it listed a large number of wastes from standard manufacturing or industrial processing operations known to contain toxic constituents. Second, the EPA also listed a large number of hazardous commercial products which became wastes when discarded. The waste lists were developed by examining some 200 studies of industrial wastes that had been compiled at the EPA prior to the RCRA legislation. From these studies approximately 125 wastes were identified as hazardous.[12] However, the EPA estimated that there were over 10.000 major industrial waste processes; therefore, the identified wastes did not begin to encompass the full gamut of hazardous wastes. To capture the full range of wastes, the EPA developed definitions for hazardous waste characteristics and required generators to test their wastes to determine whether they 
were hazardous or not. This approach is discussed below.

Industrial studies are continuing at the EPA and since the promulgation of the 1980 regulations some $10-12$ additional wastes have been identified. According to one EPA staff member, the program can never hope to cover the dynamic universe of wastes produced. Indeed, some EPA staff members feel that the lists should be dispensed with and that the regulations should rely exclusively on the characteristic approach.[13]

The final list of wastes promulgated by the EPA contained three sections. Section 261.31 listed 13 hazardous wastes resulting from non-specific sources (generic wastes) including various spent solvents, sludges, and similar material. Section 261.32 listed 76 hazardous wastes from specific sources, such as waste water treatment sludge from the production of chrome yellow and orange pigments (K003). In Section 261.33 the EPA listed more than 400 hazardous chemical products such as acetaldehyde (P023). Such chemical products became wastes only if discarded. Of these products, 196 were listed as acutely hazardous and over 200 classified as simply hazardous. The acutely hazardous wastes are subject to much tighter controls based on a quantity exclusion level.

The quantity exclusion level for wastes listed as acutely hazardous was a limited attempt by the EPA to impose a degree of hazard system. Under the RCRA regulations, a hazardous waste is to be regulated only if a generator produces more than 1000 kilograms of the waste per month. However, those wastes listed as acutely hazardous (Section 261.33e) must be regulated if more than one kilogram per month is produced. By introducing this distinction the EPA recognized that some wastes are more dangerous than others and should be subject to tighter control. The EPA also considered more detailed degree of hazard classification systems including: (a) using a threshold quantity for 
hazardous constituents of a waste to determine if regulation is required, i.e., a concentration level for partcular constitutent that must be exceeded before the waste is considered hazardous; and (b) developing degree of hazard categories for particular wastes based on their characteristics. The EPA rejected these and other suggestions for degree of hazard systems because it felt that:

"given current knowledge and information these assessments cannot be made for most wastes with sufficient precision to determine the specific quantities which represent a threshold for finding a waste hazardous. The Agency must, therefore, consider all quantities of any waste listed as hazardous." [14]

The detailed justification for listing each waste in the regulations were contained in background documents. The documents included:

1. A summary of the Administrator's basis for listing each waste.

2. A brief description of the specific industry;

3. A description of the manufacturing process;

4. An identification of waste composition, constituent concentration; and annual quantity generated;

5. A discussion of the basis for listing each waste stream;

6. A summary of the diverse health effects of each of the constituents of concern.[15]

Despite this elaborate justification, the EPA admitted that decisions to list a waste were often based on qualitative judgments, generally involving expert assumptions rather than precise field measurement.[16]

The original waste list was subjected first to internal EPA review and then, according to U.S. administrative law, was published for public comment in 1978. Although this procedure generated many comments from industry, the content of the list was not substantially revised some 6 or 7 wastes were removed as a result.[17]

Finally, the regulations also provided a procedure by which any person can petition the Agency to have a listed waste "delisted". This challenge can be 
based on: (a) the contention that the EPA reached an erroneous conclusion in its evaluation of the scientific grounds for listing, or (b) the assertion that the waste of the petitioner is different from the material on which the EPA focused in listing the waste as hazardous.[18] The first approach is significantly more difficult since it requires the petitioner to present scientific evidence rebutting the conclusions reached by the EPA, requiring extensive scientific research.[19]

These EPA lists included all three types of inclusive lists explained in the second section of this paper, i.e., generic lists of wastes arising in many industries, industry specific waste streams, and a list of chemical products to be considered hazardous if discarded.

\section{The Characteristic Approach}

As outlined above, the EPA felt that its listing procedure would not comprehensively cover the entire range of hazardous wastes. To fill in the gap, the EPA decided to require generators to test their wastes, if they did not appear on the lists, to determine if they exhibit certain hazardous characteristics. The draft regulations originally proposed eight characteristics requiring testing, but these were reduced to four in the final regulations. They include:

- ignitability - liquids with a flash point of less than 60 degrees centigrade and flammable solids or semi-solids;

- corrosivity - wastes that have a pH of 2 or less, or of 12.5 or more; or wastes that corrode steel at a rate greater than $6.35 \mathrm{~mm}$ per year;

- reactivity - wastes likely to cause acute or chronic adverse health effects in persons exposed:

- toxicity - wastes which cause acute or chronic adverse health effects in persons exposed.

The toxicity characteristic was by far the most controversial, mainly because the EPA encountered great difficulty in trying to develop testing procedures to measure toxicity.[20] The EPA finally promulgated an Extraction Procedure 
Test that specified the laboratory steps to be followed in analyzing representative samples of each waste for 14 contaminents listed in the U.S. National Drinking Water Standards. If these contaminents were present, in an aqueous leachate extracted from the waste, at levels 100 times or greater than the concentrations allowed in drinking water, then the waste is considered hazardous. This test and the "100 times" standard have been subjected to heavy criticism, due to the large scientific uncertainty involved.[21]

\section{Summary}

In summary, the regulatory system developed by the EPA to implement the RCRA legislation represents, in the words of a former Deputy Administrator of the EPA, "one of the most intricate and bewildering regulatory frameworks that exist in any area of federal law."[22] It is an attempt to devise a complete control system and in developing its classification and listing scheme, the EPA tried to cover all of the hazardous wastes being produced throughout the United States. The system included all three types of classification schemes, waste lists, characteristics, and constituents lists, although there was no mention of speciflc concentration levels. This approach presented formidable implementation challenges not only to federal authorities but also to state authorities if they chose to take over the management of hazardous wastes in their states. In so choosing, state programs were required to be at least as stringent as the federal program. In contrast, European regulatory systems and classification schemes generally are less complex and are developed with more cooperation between federal, state, and industry representatives.

\section{THE FEDERAL REPUBLIC OF GERYANY}

The Federal Republic of Germany, one of the first countries in Europe to deal with the hazardous waste problem, was also one of the first to grapple with 
classifying and listing hazardous wastes. The history of hazardous waste classification and listing begins with the Waste Act of 1972, ammended in 1976. (For a more detailed description of the Act, see in this volume Linnerooth and Davis , page -.) The Federal Waste Act was designed to deal with the disposal of all wastes. After its enactment, a series of scandals occurred concerning hazardous wastes from industry which led to pressure from the states to change the Act so it would deal more specifically with industrial wastes. On June 21, 1976, amendments to the Act were passed which led to changes in the definition of wastes and the introduction of control measures directed towards hazardous wastes including: rules for siting treatment and disposal facilities; requirements for disposal facilities to appoint plant waste supervisors; and a strengthening of penalties for violations.[23] The changes in the Act included specific authority for the promulgation of regulations defining wastes which led to the first federal list of hazardous wastes in the FRG.

\section{Two Definitions}

In Germany the term "special waste" is used rather than "hazardous waste". In the amendments to the Waste Act, two related, but somewhat different definitions of special wastes were given. The flrst definition was a technical one defining certain wastes from industrial sources that:

"because of their nature, composition, or quantity are especially dangerous to health, air, or water quality, are explosive, flammable or could promote infectious diseases, and therefore special requirements for their control are necessary."[24]

The second definition was an administrative one, stating that certain wastes:

"because of their nature and quantity should be excluded from disposal with household wastes."[25]

In the negotiations between the federal government and the states that took place prior to the passage of the 1976 amendments, the terms "hazardous" and 
"special" were completely left out of the Act. The states felt that the term "hazardous" would cause unnecessary public alarm. The term "special" did not include the wastes covered by the second definition, which are really "excludable" wastes. In the end, both the words "special" and "hazardous" were left out. The term "special" is still used, but its meaning is somewhat ambiguous. In general, "special wastes" are those referred to by the first definition above set out in Section 2, Paragraph 2 of the Waste Act.[26] However, the term special is still used by some authorities to mean any waste excluded from disposal with household wastes. This confusion has yet to be cleared up. Efforts to do so are underway and are discussed below.

Section 2 Paragraph 2 of the Act as amended, required the government to define more exactly which wastes were covered by the act by issuing regulations. However, before these regulations were issued, there had been attempts to define the concept of "waste" in general.

\section{LAGA and the Faste Catalog}

After passage of the 1972 Waste Act, which required the states to develop waste disposal plans,[27] the state governments decided they should work together in developing a nomenclature system for all wastes from which a list of special wastes requiring more stringent controls could be derived.[28] The forum for this cooperation was an organization called the Landerarbeitsgemeinschaft Abfall (LAGA), the State Working Group on Wastes. LAGA is an organization of the various environmental ministries responsible for waste disposal from the 11 German states and also includes representatives from the federal government. It has no legislative or executive functions, but serves mainly as an advisory body to the federal government, providing the state governments the opportunity to meet and work out common positions on issues regarding waste law and policy. LAGA meets twice a year in plenary session, but often 
forms smaller working committees on particular issues.[29]

In 1974. LAGA formed a working group for special wastes. The committee consisted of approximately 12 representatives from the states, the Ministry of Interior, and the Umweltbundesamt (UBA), the Federal Environment Agency, in Berlin. The the committee was charged with making the concept of "special waste" more concrete. In order to do that, the committee decided to first organize categories of wastes into a coherent system, so that the sub-set of special wastes could be more easily defined. As the chairman of the committee put it, "The catalog was really a by-product of our main objective; however, it has proven to be the more lasting contribution."[30]

The basis of the catalog was a comprehensive survey of waste producers in the FRG state of Baden-Württemberg, conducted from 1970-1973. This survey had gathered detailed data on waste types, amounts and disposal practices. The LAGA committee took the typology developed in the survey and refined it with the help of the Federal Statistics Agency. Wastes were divided into five major groups subdivided into sub-groups, and finally listed as individual waste types identified with a five digit number. The nomenclature system was a mixture of chemical compounds and generic industrial process descriptions. For example:

- Waste Number 55315 Methanol

- Waste Number 31103 Ovenash from Metal Processing

The five major categories were:

1. plant and animal waste;

2. mineral waste;

3. chemical waste from processed and synthetic products;

4. radioactive wastes;

5. municipal wastes.

Over 600 individual waste types were listed.[31] 
From this list of wastes, the LAGA group developed a smaller inclusive list of "special wastes" which in their opinion required special handling and disposal. This special waste list served as the basis for individual state regulations. These efforts were soon overshadowed, however, by a federal initiative to adopt a list of special wastes on the basis of the 1976 amendments to the Waste Act.

\section{The Federal Regulations}

In the 1976 amendments to the 1972 Waste Act, the definition of special wastes (without calling them that) in Section 2, Paragraph 2, also authorized the government to issue regulations listing wastes that were to be included in the trip-ticket control system. These regulations, listing some 86 waste types were promulgated on May 24, 1977.

The preparatory work for these regulations began at the UBA in Berlin, when the Minister of the Interior asked the UBA to develop a set of draft regulations. The in-house experts at the UBA were forced from the beginning to choose between two strategies. They could either develop an inclusive waste list based on the LAGA catalog, or put together a list of toxic constituents which, if present in a waste, would subject the waste to regulation. They also considered fixing concentration levels for these hazardous constituents in order for a waste to be controlled by the system. In the end they decided to stay with the system developed by LAGA for a number of reasons: Scientific analysis was not advanced enough to make the testing of concentration levels very practical; It would be too easy to circumvent the regulations by simply diluting or mixing wastes; The states had already developed regulations based on the LAGA catalog and a new system would have been very difficult to implement.

The UBA scientists chose wastes for their list based on the following criteria: 
- Source of the Waste

- Composition

- Amounts Produced

- Disposal Practices

- Environmental Dangers

These criteria were not weighted in any quantified manner, but one of the compilers of the list felt that emphasis was placed on the environmental dangers of the substances in the wastes.[32] This process led to a rather long list of wastes that was then shown to state authorities for comment. The states protested at the length of the list and felt that the federal regulations should only include those wastes that were produced in all of the states.[33] Industrial associations were also involved in discussions about the list after a first draft was prepared by the UBA. In addition, the UBA considered the lists of other countries (the Netherlands, Denmark, and Canada) and the list proposed for an European Economic Community Directive on hazardous wastes. Finally, a much smaller list was submitted by the UBA to the Ministry of the Interior which adopted it in its regulations. This list was to be used, not as a comprehensive list, but as a description of the most problematic wastes that should be controlled by all of the states.[34] There was no procedure given for adding or subtracting wastes from this list, but state governments had the authority to require trip ticket regulation for other wastes and some did increase the number of regulated wastes substantially (see the discussion of Bavaria and Hesse below). The federal regulations contained no explicit production quantity cut-offs as did the U.S. regulations for the wastes listed. But rather, the FRG chose to subtly add quantity considerations in the description of the source of the waste, which was done as follows. Column 1 of the list gives the generic name of the waste, Column 2 gives the chemical name and the waste number, and column 3 lists the industrial source of the waste. For example: 


\section{Column 1}

Halogen Containing

Organic Solvents

\section{Column 2}

Chlorobenzene 55202

Chloroform 55203

\section{Column 3}

From the Chemical Industry, Gas Works, Pharmaceuticals

In listing the sources in Column 3 , the UBA listed only those industries, or production processes that they thought would produce significant quantities of the listed waste. So a waste comes under the regulations if it is listed in columns 1 and 2, and is produced by one of the industries or as a result of one of the processes listed in column 3 . The same waste, produced by an industry not given in column 3 is not covered by the federal regulations.[35]

In contrast to the EPA in the U.S., the UBA relied only on the listing method for classifying hazardous wastes. It did not adopt the characteristics approach for identifying hazardous wastes not covered by the lists. They felt that the scientific analyses required for testing waste characteristics were both difficult to standardize and would place unacceptable cost burdens on industry. The listing of the hazardous constituents was considered, but for the previously mentioned reasons, rejected.

\section{State Lists - Bavaria and Hesse}

In addition to the 86 wastes that must be controlled under the federal regulations, state environmental authorities were free to require trip-tickets and other controls for additional wastes. The two German states that became most actively involved in hazardous waste regulation were Bavaria and Hesse. Their waste lists make an interesting comparison to the federal one.

Bavaria had developed, before the federal regulation, its own waste list. This list was also based on the LAGA catalog but included quantity cut-offs for four classes of waste. For each category, there was a minimum amount that had to be produced in order to trigger regulation. 


$\begin{array}{lll}\text { Class I } & 1 & \text { ton/year } \\ \text { Class II } & 10 & \text { ton/year } \\ \text { Class III } & 100 & \text { ton } / \text { year } \\ \text { Class IV } & 1000 \text { ton } / \text { year }\end{array}$

This was, in effect, a degree of hazard system with the wastes in Class I the most hazardous, those in Class II less so, etc. It was put together by scientists within the Bavarian Ministry Land Development and Environment with some consultation with industry experts. Since Bavaria had very early constructed treatment facilities (see in this volume, Linnerooth and Davis, page --) it already had a good idea of the amounts and nature of wastes being produced in the state. These regulations had to be scrapped, however, when the federal regulations were adopted since they did not match the federal system. Bavarian authorities expressed frustration at having developed its system too early and then being forced to change it at considerable cost.[36]

Bavaria finally promulgated new regulations with a list that incorporated the federal one plus those wastes that it wanted to regulate in addition. They printed the entire LAGA catalog in their regulations and distinguished four types of wastes with the following designations in the catalog.

\section{Marking}

$\mathrm{X}$

$\mathbf{N}$

Bold Print

No Marking

\section{Explanation}

Wastes that should generally not, or only under certain conditions, be disposed of with hou sehold wastes, but do not require a trip-ticket.

Wastes that require a trip-ticket and special disposal.

Wastes that under the federal regulations require a trip ticket and special disposal.

Wastes that can be disposed of with household wastes.

In addition to the 86 wastes covered by federal law. Bavaria added 153 wastes to 
its list for a total of 239 wastes under its regulatory system.[37]

The state of Hesse also began early to regulate hazardous wastes. This was the result of some highly publicized scandals in the early 1970s in Hesse which led to public pressure for more active government control. This pressure led to the organization of the central Hesse authority for hazardous waste disposal, HIM (see Linnerooth and Davis, p. --) and to state regulations. The waste list developed by Hesse was also based on the LAGA catalog. Again, in-house scientists advised the Environment Ministry in Hesse as to which wastes to regulate. Hesse divided the wastes listed in the LAGA catalog into three categ ories, based not on quantity cut-offs, but on which kind of disposal was best suited for a particular waste. The three categories are:

- Category 1: Wastes that generally can be disposed of with household wastes.

- Category 2. Industrial wastes that cannot be disposed of with household wastes and must be disposed of in special waste facilities, for example, secure landfills.

- Category 3: Industrial wastes that are especially hazardous require special disposal techniques in special waste facilities, for example. special incineration or deposition. [38]

These categories in effect produced a degree of hazard classification system based not on quantity cut-offs as in the U.S., but on guidelines on how to dispose of particular wastes. Such a system reflects degree of hazard if one assumes that treatment categories are ranked according to risk. There are exceptions; for example, heavy metal wastes might be disposed of more safely in a landfill (category 2) than by incineration (category 3 ).

In developing this system, authorities in Hesse consulted with industry trade associations on the make-up of the list. At first, industry was very resistant to the system and many meetings and conferences were held with industry by the State Environment Ministry. In the end, the authorities persuaded them that the system would both be easier, and reduce both analysis costs and the 
time required to process wastes.[39]

The final Hesse list included 312 waste types in categories II and III, including the 86 wastes in the federal regulations. Hesse, therefore listed over 70 more wastes to be regulated than Bavaria. Ironically, two of the states, which had pushed for a short federal list, went on to develop considerably longer lists on their own, and significantly different systems of classification. These differences led to problems in tracking of cross-state shipments of hazardous wastes and has led to pressure for the development of a more comprehensive federal system.[40]

\section{Proposed Changes in the Federal Regulation}

Because of the difficulties presented by the differing waste lists of the states, work is currently underway in the FRG with the aim of developing a more comprehensive, unified list for all of the states. This time the work is being conducted by the LAGA, not the UBA, again by a smaller working group.

The group is currently revising the LAGA waste catalog and is proposing to develop a special waste catalog, i.e., listing only those wastes that should not be disposed of with household wastes. (This was also the goal of the earlier LAGA working group.) This new catalog would categorize special wastes by the preferred disposal method, similar to the Hessian three category system, but also reflecting some refinements made by Austria (see below) in developing its hazardous waste regulations. The LAGA hopes that this special waste catalog will be promulgated by the federal government as binding for all the states, greatly enlarging the current federal waste list.[41] This time, because the LAGA is compiling the list, and all the states are represented, it will be difficult for the states to object to the system. Again industry consultation is planned before a final list is developed. Industrial trade assóciations do not participate directly in development of the list, but when the LAGA has a draft, it plans to 
discuss it with industry. Also, the group plans to conduct discussions with some environmental groups in the FRG who are beginning to take an active interest in the area of hazardous waste management.

The FRG's somewhat pioneering work on the listing of hazardous wastes has served as a model for other countries in Europe. For example, Hungary, in its hazardous waste legislation, adopted the catalog originally published by LAGA and refined by Hesse. Austria has also made extensive use of the FRG catalog in developing its own hazardous waste regulations. Austria's system will be briefly discussed below.

\section{AUSTRIA}

Austria began relatively late to develop a hazardous waste control system. As in other industrialized countries, several well-publicized scandals concerning illegal dumping and poor management of wastes spurred regulatory action. Austria passed its Special Waste Act to deal with the problem on March 2, 1983, and it went into effect on January 1, 1984. When the Austrian authorities had to identify wastes to be controlled, they took advantage of their late start to observe the experiences of other countries. However, the mechanism by which they developed their waste list is unique in the way cooperation between industry and government was carried out.

The task of developing a waste list in Austria was given to the Oesterreichishes Normungsinstitut, The Austrian Standards Institute, a non-governmental, technical standard setting body that advises the government on a whole variety of standards--from fire extinguishers to the size of trash cans. Its work is conducted by a number of Fachnormenausschusse (FNA), Expert Standard Committees. These committees are divided into smaller working groups on particular subjects. The membership of the FNAs includes representatives from federal, 
state, and local government, scientific experts from the academic community and industrial representatives, usually from industrial trade associations and trade unions. When the FNAs divide into working groups they also may invite experts from outside the FNA to assist them. [42]

The Standards Institute's FNA-157 for Waste Disposal was given responsibility for developing a waste list by the Federal Ministry for Health and Environment. As a first step the FNA defined the term of special waste for Austria:

"Special wastes are solid or liquid wastes which because of their composition or quantity cannot be disposed of with municipal waste, ie., household garbage, without special preparation. [43]"

This was an administrative definition similar to the one used in FRG. On the basis of this definition the FNA developed a special waste catalog that was patterned after the FRG catalog and used the same 5 digit numbering system. But it contained only special - not all - wastes listing over 400 waste types. In addition, this catalog, rather than specify the source of the waste listed, gave the treatment methods best suited for disposal of each of the wastes listed similar to the system developed in Hesse in the FRG. The methods included:

1. municipal landfill

2. special waste landfill

3. municipal incinerator

4. special waste incinerator

5. composting

For each waste the recommended treatment method was indicated by a numbering system indicating if the method was 1) suitable; 2) suitable under certain conditions; 3) not suitable. This system effectively resulted in a degree of hazard classification system. For example, waste number 55315, methanol, was listed as not suitable for a municipal landfill, conditionally suitable for a municipal incinerator, and suitable for either a special waste landfill or special incinerator. [44] 
The development of the catalog was relatively uncontroversial since it was non-binding legally and only made recommendations. Controversy arose when the Ministry of Environment asked the FNA to develop from the catalog a list of hazardous special wastes, to be regulated under the Austrian trip-ticket system required under its new legislation. The Ministry agreed to accept in its regulations a list, and the compromises it involved, worked out within the FNA. However, if the FNA failed, the Ministry would develop its own list.

To produce this list of hazardous special wastes the special waste working group of FNA-157 expanded its membership to a record 120. The majority of the members were industry representatives from trade associations and firms, but also included federal, state, and local government officials and a few scientific experts from universities.

Because of the unique interest in the issue, the FNA decided in this case to allow any industry representative who asked to participate (usually only selected representatives are chosen by the FNA). However, certain environmentalists who asked to participate were excluded, namely a group called "Critical Chemistry". The FNA voted not to allow this group to participate with the reason that "there were already enough chemists on the committee."[45] It also decided, in a change of the rules, to allow the entire working group and the members of the FNA to vote on the final list of wastes. The working group formed a smaller sub-group of 15 members to make an initial selection of wastes for the list. They began by listing those wastes in the special waste cata$\log$ that were designated as requiring the most stringent disposal methods. They also examined the hazardous wastes list of other countries, most notably the FRG and Switzerland. Their draft list contained some 160 wastes, which was then reduced in a negotiation process within the full working group.

Interestingly, the rules of the Standard Institute required that working 
groups reach decisions unanimously. A member of the group told us that the representatives from particular industries protested the inclusion of their wastes on the list, and they theoretically could have vetoed any decision. But there was strong pressure to compromise, because the Ministry of Health and Environment could always take over the process if agreement was not reached. He claimed they were most often persuaded by health effects arguments made by the scientific experts. In addition, the earlier classification system developed for the special waste catalog, put together with the help of industry representatives, gave clear guidelines for which wastes to include. It was very difficult for industry representatives, who had accepted that catalog, to argue for changes in its principles.[46]

Finally a compromise list of 148 wastes was agreed upon and published by the Standard Institute for public comment. About 25 objections were submitted, reviewed by the FNA, and rejected. The list was published in final form on December 1, 1983.[47] It was agreed in the FNA to call these wastes "special wastes requiring supervision," rather than hazardous special wastes because, as in the FRG, they wanted to avoid public alarm. On February 9, 1984, the Ministry of Health and Environment issued regulations that declared the list binding and introduced a trip-ticket system for all of the listed wastes. The regulations also introduced quantity production cut-off levels similar to those in the U.S. For nine waste types, the wastes are regulated if more than 20 kilograms per year (kg/year) are produced. For all other wastes listed, $200 \mathrm{~kg} /$ year must be produced before regulation is required.[48]

In summary, the Austrian system like that of FRG, relies on an inclusive hazardous waste list and does not include characteristics or constituent approaches. It does, however, use quantity cut-offs in an informal degree of hazard system as in the U.S., and makes recommendations as to the appropri- 
ate disposal method, similar to Hesse's three category list. The most interesting aspect of Austria's list is the process by which it has developed, especially the degree of industry participation in the process. We will now discuss this issue and others in more detail.

\section{THE INSTTTUTIONAL FRAMING OF' HAZARD}

The case studies of the development of hazardous waste classification systems in the United States, the Federal Republic of Germany, and Austria illustrate how both science and institutional needs shaped the regulatory programs that were constructed. In addition to the scientific uncertainty surrounding definitions and classification systems for hazardous waste, the rules adopted in each country, and therefore the outcomes of an apparently scientific problem, ultimately reflect political and legal frameworks, the objectives of each country, and explain the difflculties encountered by international organizations attempting to develop standardized classification systems.

\section{Dealing with Scientific Uncertainty}

In developing hazardous waste classification systems, science is constrained and shaped by institutional needs. One of the most important constraints in hazardous waste control is that the scientific information concerning the hazards associated with these wastes is either uncertain, unknown, or unknowable (for a further discussion see in this volume Wynne p.--). The role of science is illustrated by the deliberations over using degree of hazard systems for classifying wastes. Both the FRG and the U.S. have seriously considered, but decided against, developing complicated degrees of hazard systems for their regulatory control programs, including establishing concentration levels for hazardous constituents in a waste that must be exceeded before it is regulated. Few dispute the theoretical advantages of classifying wastes by different 
levels of risks so that the control systems could be designed and resources allocated accordingly. Unfortunately, the information needed for such classification is difficult, if not impossible, to obtain. The "hazard" of waste depends on a variety of factors including physical form, composition, concentration of constituents, toxicity of constituents, method of disposal, etc. All of these factors are difficult to measure and standardize in some form of classification system. Toxicity testing, for example, is filled with uncertainty concerning dose-response relationships, extrapolating animal models to humans, and the lack of standardized testing procedures. The fate of wastes once disposed can vary depending on the properties of the waste, i.e., solubility, volatility, pH, etc., and the conditions of disposal, i.e., soil conditions, geology, etc.[49] Such uncertainties led the EPA to conclude:

"The agency does not believe any of the degree of hazard systems suggested by commentators (or any the Agency could itself conceive) are capable of actually distinguishing different degrees of hazard among the myriad hazardous wastes and also relating manag ement standards to the degrees in a technically and legally defensible ways.[50]"

However, the EPA, because of political and economic pressure, did introduce a limited degree of hazard system with its distinction of small quantity cut-offs for some acutely hazardous wastes. Federal authorities in the FRG also rejected the idea of introducing a formal degree of hazard system in their regulations. On the other hand, state authorities there have not been as reluctant. Hesse, with its three categories of wastes, has in fact used a simple degree of hazard system. In the U.S. several states have adopted degree of hazard systems in developing their own regulations to implement the RCRA program.[51]

An interesting comparative example is the Netherlands. In regulations implementing its Chemical Waste Act, the Netherlands differentiated between four classes of hazardous wastes and determined concentration limits of chemical constituents for wastes to be considered hazardous.[52] These were rather 
arbitrarily fixed by negotiation between the Ministry of Economic Affairs, representing industrial interests, and government waste disposal experts. Other countries have expressed an interest, and industries have lobbied heavily, for using such concentration limits in hazardous waste regulation, but outside the Netherlands they have been rejected as impractical, for several reasons. First, it is very difficult and time consuming to sample and test wastes to determine the concentrations of particular substances. Second, the spirit of the regulations could easily be circumvented simply by diluting or mixing wastes so that hazardous constituent concentrations are below the cut-off point.

The notion of classifying hazardous wastes on the basis of degree of hazard is so compelling, that pressure for the adoption of such systems will undoubtably increase. But regulators faced with developing such systems, and limited by scarce resources, will have to carefully consider whether complicated, precise classifications are possible given the fundamental uncertainty of the scientific information on hazardous wastes. For example, as Giandomenico Majone has pointed out:

"...even in the United States with its enormous scientiflc, technical, and financial resources--no more than 500 chemicals can be tested each year because of the limited availability of trained toxicologists, laboratory facilities, and test animals. This is barely sufficient to keep up with the flow of new chemicals, let alone to investigate the existing stock of well over 50,000 chemicals in commercial use. International cooperation in toxicological testing would have obvious benefits; but serious (if ill-understood) differences in methodology, risk philosophies, and regulatory approaches make cooperation difficult, and even reduce the value of the limited amount of information that is available."[53]

It should be mentioned that the Organisation for Economic Cooperation and Development (OECD) has been relatively successful in developing international protocols for toxic goods. Wastes, however, are much more difficult to test because of their heterogeneous nature. Hazardous goods are often tested 
by procedures to ensure quality control, but there is little incentive for such testing of wastes.

\section{Political Objectives}

Because of the inherent scientific uncertainties involved in hazardous waste classification, it is not surprising that the process used and the outcomes achieved reflected the political and social goals of the regulators. In the United States, the original goals of the RCRA program were to control all hazardous wastes generated in the U.S. This comprehensive system was clearly mandated by Congress because it felt that a uniform system was necessary in order to ensure that some states would not become "dumping grounds" for others.[54] Later, as the EPA began to develop its regulations, the legal and economic constraints of a total control system began to be recognized and compromises in the philosophy of total control were introduced, such as the procedure for delisting wastes and the exclusion of small quantity generators from the regulations.

In the FRG, the purpose of federal regulation was not to develop national all-inclusive standards. As with other types of regulation, the responsibility for implementing hazardous waste control was handed to the states. Federal regulations identified only those wastes that needed to be controlled in every state but the states were allowed to develop and greatly expand their own classification systems. The decision not to adopt a constituent list approach in the federal regulations was also based in part on the fact that state governments had already developed their systems from the LAGA catalog. This deference to state authority and the traditional role of the UBA as a technical advisor, not as regulator and supervisor (the role of the EPA in the U.S.), is reflected in the hazardous waste control system that was developed. The disadvantages of the system. namely that decentralized control can lead to 'wide 
disparities between the different state regulations and make cross-border transport more difficult, has now led to pressure for a more centralized classification system and standards.

Finally, in Austria, the implementation of the system was thought to be impossible without the consent and cooperation of industry. The traditional spirit of social partnership. holds that all social and economic problems can be dealt with through negotiation and cooperation between government, industry, and labor unions. [55] This belief led to a process that from the beginning involved both industry and government in developing a compromise list of wastes, with the explicit recognition that the definition hazard was politically constructed (whether wastes were to be included was voted on).

\section{Scientific Justification}

In addition to the different political goals that influenced the process of hazard classification in the countries studied, there were differences in the amount and kind of scientific evidence presented to support the inclusion of certain wastes on the lists. In the U.S. each individual waste was supported by a background document giving detailed justification for the listing of a particular waste. Such detail is supplied in part as a precaution against future legal challenges. As Ronald Brickman et al have pointed out in their comparison of carcinogen regulations in four countries, the courts in the U.S. play a much broader role in reviewing administrative action than in Europe. For example, they point out that public interest groups and industry enjoy a much more liberal access to the courts in the U.S. than in the FRG or Austria, where rules for who can have access to courts are much more restrictive. In addition, U.S. law offers comparatively clearer definitions of agency responsibilities, and statutory deadlines which have allowed environmental groups and industry over the last 15 years to challenge (or compel) agency actions. Finally, U.S. courts have gone 
beyond procedural scrutiny to review the substantive basis for agency decisions, while European courts have been much more deferential to agency findings of fact.[56] More active judicial review in the U.S., in part, led the EPA to provide elaborate justifications for listing wastes, while no such detailed justifications were deemed necessary in the FRG or Austria. But, in addition to such legal differences, American and European approaches to regulation reflect long-standing traditions in Europe that rigid, statutory regulations are less effective than standards and codes developed in cooperation with industry.[57] In contrast, U.S. approaches to environmental regulation have been much more adversarial in nature, reflecting a need to force industry to comply with rules protecting the public health and the environment. Even when the agencies were reluctant to take on such adversarial roles, they were often compelled to do so by pressure from public interest groups and/or judicial action.

\section{Political Legitimacy}

These differences in the handling of scientific uncertainty, political goals, and scientific justification all reflect cultural differences inherent in the approaches chosen by the different regulatory agencies trying to legitimate their actions. In the U.S., the regulatory philosophy that guided the development of the hazardous waste regulations was adversarial and characterized by centralized expertise and control. Interest groups were only allowed to comment on published draft regulations, not participate in their development. In the FRG, expertise and control was more decentralized, with regulatory responsibility in the states and the federal agencies mainly playing an advisory role. Consensus on regulatory objectives was sought, through the LAGA, between levels of government, not between government and interest groups. Discussions with interest groups were held often after regulatory strategies were chosen. but before regulations were finalized and published. At the other extreme. 
Austria, at an early stage, explicitly involved government and industry (although it excluded environmentalists) in a process that reflected traditional values of cooperation through social partnership. Although this process ensured acceptability among the industry interest groups, it did leave the government open to harsh criticism from environmentalists and the media.[58] These countries represent a continuum of adversarial versus cooperative philosophies of regulation. Similar differences have been observed in the area of carcinogen regulations and occupational health standard setting.[59,60].

These differences in regulatory practice explain, to a large extent, the difficulty in developing international hazardous waste classification systems. However, some limited consensus has been achieved. The European Economic Community has issued a Directive on Toxic and Dangerous Wastes that lists 27 waste categories to be regulated by the member nations. A NATO study identified 38 waste types that were regulated in three or more NATO countries.[61] Work is underway at the OECD in Paris to develop a means of crossreferencing a waste listed in one country to the list of another.[62] But this basic consensus has not led to standardization because the systems operating in the various countries must be more detailed and reflect fundamental political, social, and cultural differences.

\section{CONCLUSIONS}

The case studies clearly show that what appears a straightforward scientific exercise, namely the definition and classification hazardous wastes, is not straightforward at all. Rather, the definition of hazard ultimately depends on the political and institutional framework and objectives for which the definition is being developed. Scientific information, characterized by large uncertainties, can legitimately be molded to fit other needs. This analysis suggests that more attention must be given to defining the realistic goals of 
$-33-$

hazardous waste definition and classification in light of institutional and political constraints so that these goals can have a reasonable chance of being achieved. 
REFERENCES

1. Dr. Bernd Wolbeck, "Political Dimensions and Implications of Hazardous Waste Disposal, in Hazardous Waste Disposal, John P. Lehman, ed. New York: Plenum Press, (1983) p. 8

2. Interview with Ted Finnecy, Harwell Laboratory, U.K.

3. John P. Lehman, "Hazardous Waste Definition and Recommended Procedures" in Hazardous Waste Disposal op cit. p.45.

4. Samuel S. Epstein and Lester 0. Brown, Hazardous Wastes in America, Sierra Club (1982), p. 3.

5. John Quarles, Federal Regulation of Hazardous Wastes: A Guide to RCRA. Washington, D.C.: The Environmental Law Institute (1982), p. 3.

6. Resource Conservation and Recovery Act, Public Law 94-580. October 21, 1976.

7. Federal Register, Volume 45, Number 98, Monday (May 19, 1980), p. 33106.

6. Ibid., p. 33121.

9. Ibid., p. 33113.

10. Interview with Gary Dietrich, Former Head, Office of Solid Waste, Environmental Protection Agency.

11. Jack McKee and H.W. Wolff (eds.), Water Quality Criteria, The Resources Agency of California, State Water Resources Control Board (1971).

12. Interview with Gary Dietrich.

13. Interview with Matthew Strauss, Environmental Protection Agency, Washington, D.C.

14. Federal Register, op cit. p. 33112.

15. Ibid., p. 33113.

16. Ibid., p. 33114 . 
17. Interview with Gary Dietrich.

18. Quarles, p. 56.

19. Ibid., p. 57 .

20. Ibid., 54 .

21. Federal Register, op cit. p. 33112.

22. Quarles, p. 3.

23. Reinhard Kuntze, "Das Abfallbeseitigungsgesetz", Der Landkreis, 8-9 (1977), p. 282.

24. German Waste Act, Section 2, Paragraph 2.

25. Ibid., Section 3, Paragraph 3.

26. Gottfried Hosel and Heinrich Freiherr von Lersner, Recht der Abfallbeseitigung. Berlin:Erich Schmidt Verlag, pp. 1120-1122.

27. German Waste Act, Section 6.

28. E. Merkel, "Abfall: Uebersicht und Bewertung," Wasser und Boden, 8 (1976), p. 207.

29. Correspondance with Minister of Nutrition, Agriculture, and Forests, Silesia-Holstein, Germany, current chairman of LAGA.

30. Interview with Barthl Fürmaier, Bavarian Ministry for Land Development and Environment.

31. E. Merkel, p. 209.

32. Ekkehard Ofihaus, "Ueberwachung der Beseitigung bestimmter gewerblichen Abfälle", Der Landkreis, 8-9 (1977), p. 299.

33. Interview with Axel Szelinski, UBA, Berlin.

34. Thomas F. Weinheimer, "Besonders Ueberwachungsbedurftige Abfälle", Umwelt, 3 (1977), p. 223.

35. Ibid., p. 227.

36. Interview with B. Fürmaier. 
37. Bavarian Waste Regulations from August 10, 1978.

38. Waste Catalog of Hesse, October 1981.

39. Interview with Carl O. Zubiller, Hesse Ministry of Environment.

40. Interview with A. Szelinski.

41. Interview with C.0. Zubiller.

42. Information on the process of listing hazardous wastes in Austria was given in an interview with Dr. Gerhard Vogel, a professor at Vienna's Business University and a member of the Standard's Institute Expert Standard Committee on Waste Disposal.

43. Oe-Norm S-2000, Abfall Begriff, Oesterreichisches Normungsinstitut.

44. Oe-Norm S-2100 Sonderabfallkatalog.

45. Josef Votzi, "Steyrer's Mũll Abfuhr" Profil March 5, 1984, p.21.

46. Interview with Dr. G. Vogel.

47. Oe-Norm S-2101 Ueberwachtungs bedürftrage Abfülle.

48. Regulations for the Control of Special Wastes, the Austrian Federal Minister for Health and Environment, January 19, 1984.

49. Office of Technology Assessment, Technologies and Management Strategies for Hazardous Waste Control, Washington, D.C., March 1983, p.229.

50. Federal Register op cit. p.33104.

51. OTA p.237

52. Jan Dirven "Aspects of Hazardous Waste Policy in the Netherlands" IIASA. November 1983, mimeo.

53. Giandomenico Majone, "Prevention and Health Standards: American, Soviet and European Models" Journal of Health Politics and Law 7(1982), p.630.

54. OTA p.269.

55. Egon Matzner, "Social Partnership" in The Political System of Austria Heinz Fischer ed., Vienna: Europa Verlag, 1977. p.432. 